\title{
Profile of clients of different providers of family planning services in Egypt [Arabic]
}

Population Council

SPAAC

Follow this and additional works at: https://knowledgecommons.popcouncil.org/departments_sbsr-rh How does access to this work benefit you? Let us know!

\section{Recommended Citation}

"Profile of clients of different providers of family planning services in Egypt [Arabic]," Research summary. Cairo: Population Council and Social Planning, Analysis \& Administration Consultants (SPAAC), 1996. 


\section{ملخص نتائج دراسة}

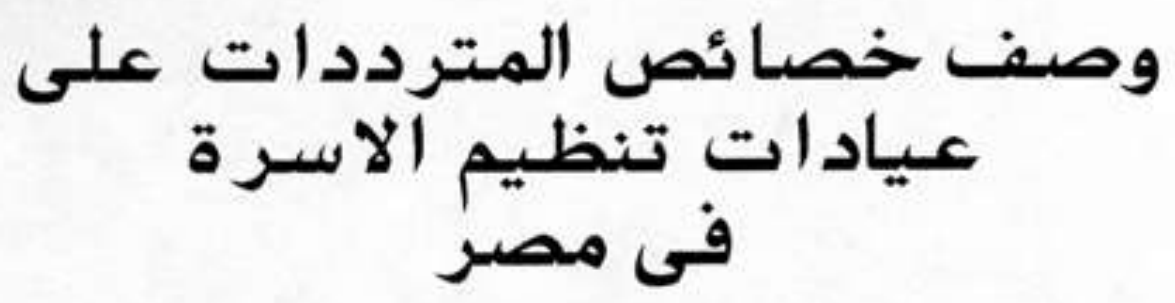

$$
\begin{aligned}
& \text { مستشارو التحليل و التخطيط الاجتماعنى و الادارة (سباك) } \\
& \text { بالتعاون مع العوانع }
\end{aligned}
$$

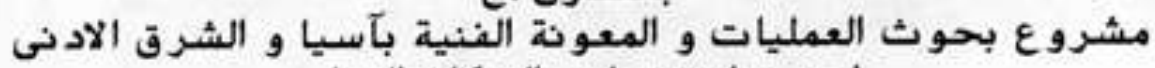

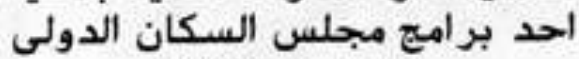

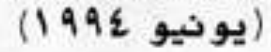


بدأت الحكومة المصر ية مشرو عها القومى لتنظيم الاسرة فى عام 977 أو وكان هذا

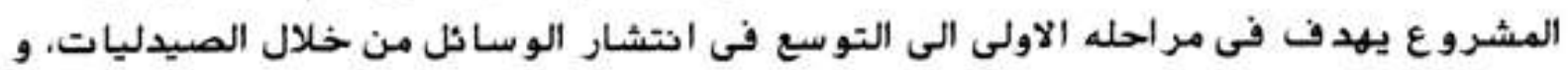

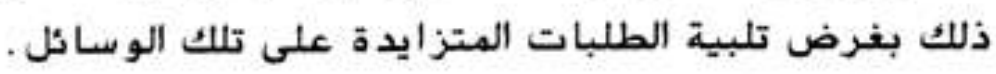

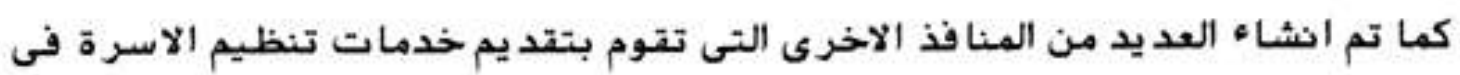

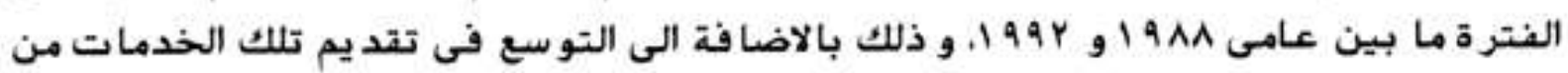

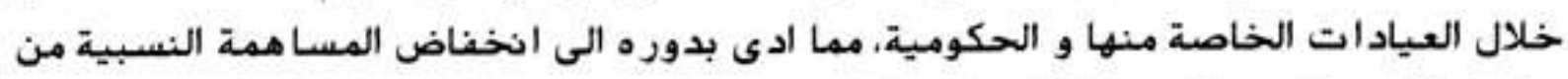

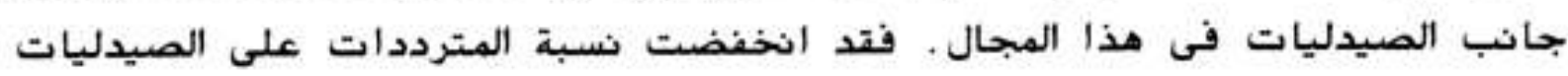

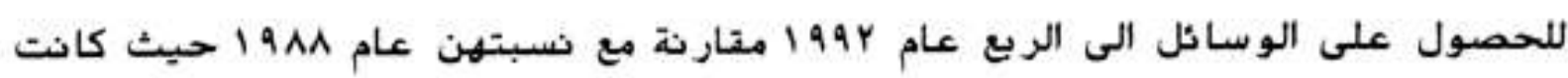
النصف . و يرجع السبب فى ذلك الى : النهي ظهور العد يد من مشرو عات تنظيم الاسرة ة.كمشرو ع تحسين خدمات تنظيم الاسرة (CSI)

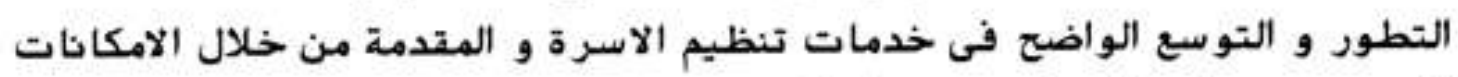

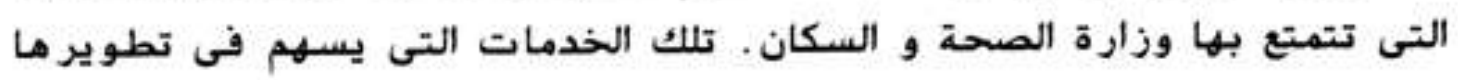

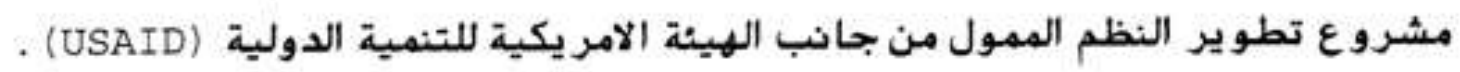

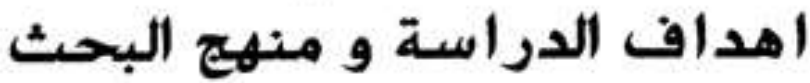

ظهرت الحاجة الى تو فير معلومات دقيقة و واضحة عن المترددات على منافذ

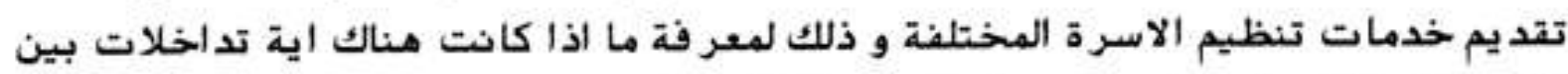
الانشطة و الخدمات التى تقدمها مذة المنافذ المختلفة .

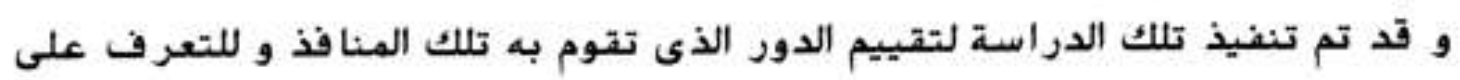

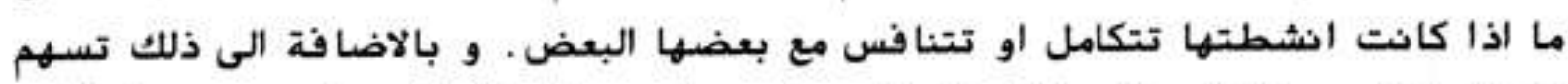

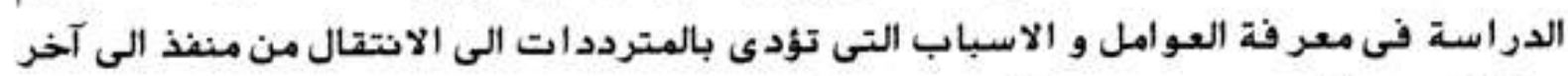

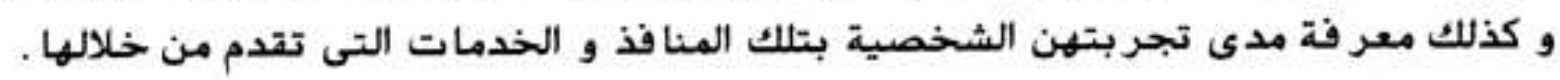

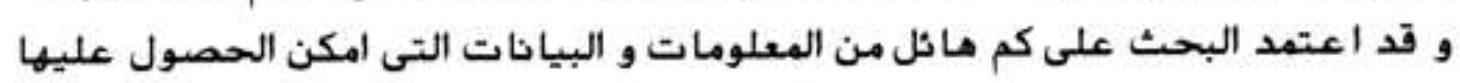

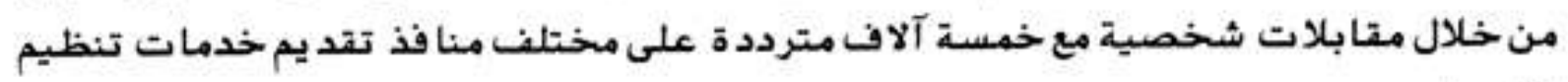

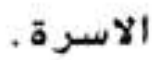

و قد تم اختيار العينة من ستة محافظات مختلفة روعى فى اختيار ها انتماء المترددات الى مختلف القطاعات الاجتماعية السكانية و الاقتصاد ية، و و الى جانب العانب التأكد من التغطية الجغرافية الشاملة. و قد قام بتنفيذ هذة الدراسة مستشارو التحليل و التخطيط الاجتماعى و الادادارة

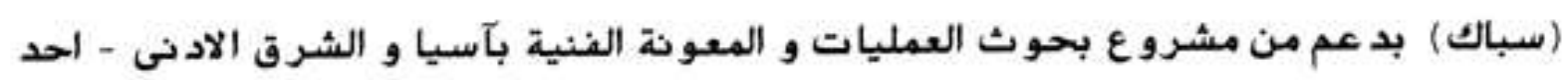


برامج مجلس السكان الدولى و ذلك في يو نيو ع9919. نتائج الدراسـة مجة الدان

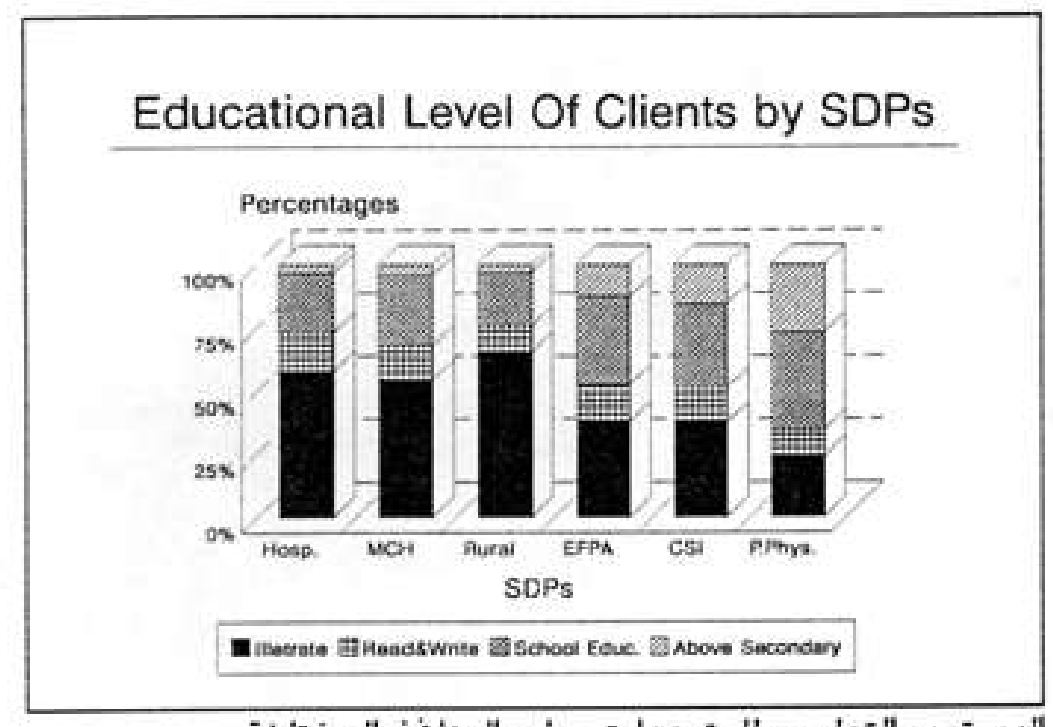

المستوى التعليمى للمترددات على المئا فذ المختلفة
بعيدا عن مدى التد اخلات

بين الاثشطة و, الخدمات التى تقدم عبر منافذ تقديم خدمات تنظيم الاسرة فقد اوضحت النتائج ان المترددات على مئ اكز تقد يم الخدمة بالوحدات الريفية ينتمين الى الطبقة الدنيا

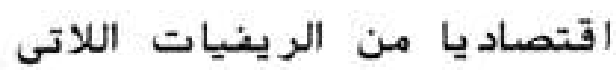
غالبا مـا يستخدمن الحبوب . أما

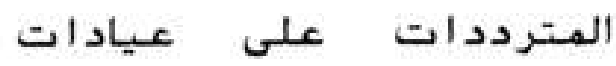
المستشفيات فهن سيدات من

المدن و الريف من ذوات الدخل الضنيل و غنالبا ما يلجأن الى تلك العيادات بحثثا عن خدمات تنظيم الاسرة بالاضافة الى الخدمات الخاصة بامراض النساء و التوليد . كما اظهر ت النتائج ان المترددات على العيادات التابعة للجمعية الهصر ية لتنظيم الاسرة غالبا ما يكن من سنكان المناطق القريبة من تلك العيادات و يطلبن خدمات تنظيم الاسرة . اشـارت الدراسة الى اهم العوامل التى تبحث عنهها السيدة عند التردد على منافذ فئد

تقد يم الخدمة.

مستخدمات تنظيم الاسرة . . . من هن؟؟

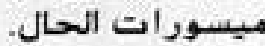

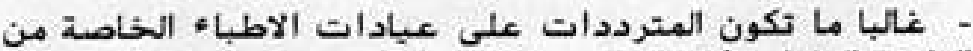

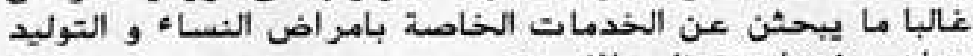
بجانب خدمات تنظيم الاسرة

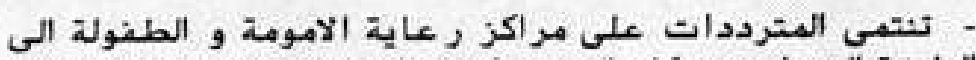

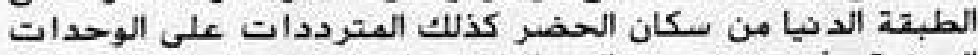

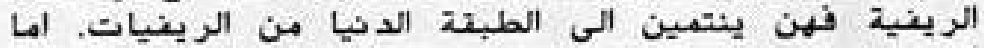

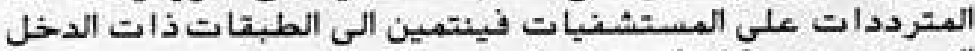
المحدود من سكان الر يت و الحضر

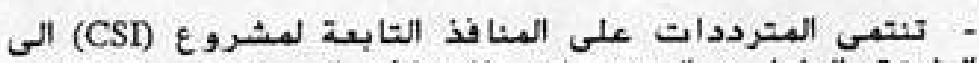

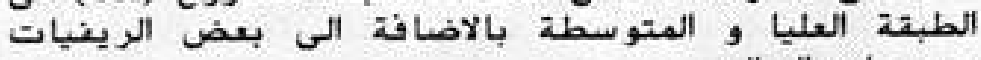

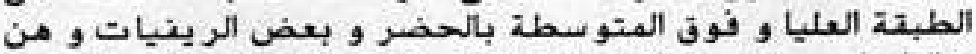

قتد وجد ان السبب

الرثيسى وراء تردد السيدات

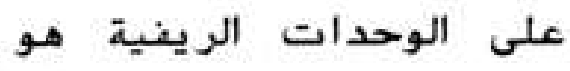
سـهولة الوصول لتلك العيادات و كذلك قلة تكلفة الخدمة المقدمة. كما تعتبر تلك الاسباب هى ثفس الاسباب التى تؤدى ببعض المترددات الى اللجحوء الى وحدات رعاية الامومة و الطفولة و ذلك الك بالاضافة الى ارتفاع مستوى مقدمى الخدمة بتلك المنافذ. كما ذكرت المترددات على مراكز تقديم الخدمة بالمستشفيات ان تكلفة تقديم الخدمة مناسبة لهن جدا، كذلك اشـادوا بارتفاع مستوىى مقدمى الخدمة. 
و اكد ت الهترددات على العيادات التابعة للجمعية المصر ية لتنظيم الاسرة على تلك الاسباب الثلاثة السنابق ذكر هـا بالاضافة الى حسن المعاملة من جانب مقدمى الخدمة كما اكدن على اهمية وجود طبيبية.

تعد الآثار الجانبية و المضاعضات الثاتجة عن استخد ام بعض الو سائل او عدم الرضا عن الوسيلة المستخدمة - - مـن اهم العوامل التى تؤدى الى ترك الصيدليات و الوحدات الريفية و كذلك مز اكز رعاية الامومة و الطفولة و الانتقال منهها الى منافذ اخرى لتقديم الخدمة ، كذلك تعتبر تلك الاسباب هى نفسها التى تؤدى ببعض المترددات الى الانتقال من بعض المنا فذ الاخرى و لكن بنسبة اقل من السابق ذكر هـا. كما ان صعوبة الوصول الى منفذ تقذيم الخدمة يعد من اهم الاسباب التى تؤدى بالمتردد ات على العيادات التابعة لمشروع (CSI) ، و المترددات على المستشـفيات و كذلك المترددات على عيادات الجمعية المصرية لتنظيم الاسرة الى الانتقال من تلك المنا فذ الى منافذ اخرى . و اشارت العديد من المترددات على عيادات الاطباء الخاصة ان ارتفاع تكلفة الخدمة يعد من اهم اسباب تركهم لها و انتقالهم الى مكان اخر لتقد يم الخدمة. اكدت الدر اسـة على ضعف معر فة المترددات بالمنا فذ الاخرى لتقد يم خدمات تنظيم

الاسرة. فقد اوضحت النتاثيج معرفتهن بالبعض المتمثلة فى الاطباء الخصوصيين و المستشفيات و عيادات (CSI) اكثر من معر فتهن بباقى منافذ تقد يم الخدمة. فتليلات منهن مثلا على علم بعيادات الجمعية المصرية لتنظيم الاسرة.

مصادر معلومات المترددات عن مر اكز تنظيم الاسيرة

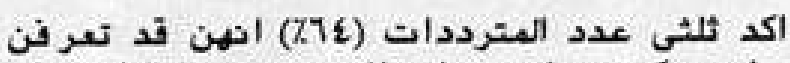

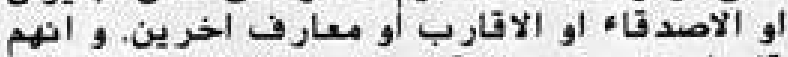

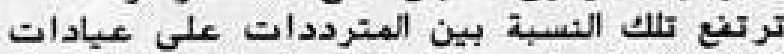

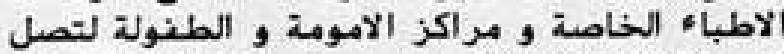

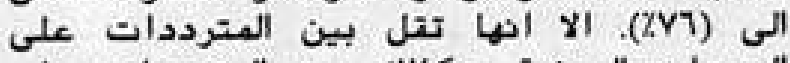
عيادات (CSD).

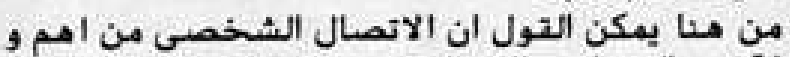
الخاصة بخدمات تنظيم الاسرة لفئ.

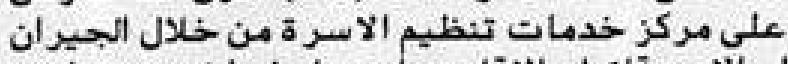

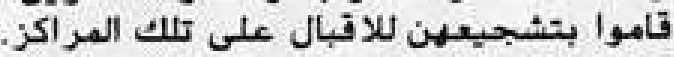
الوحدات الريضية و كذلك بين المترددات على على التى

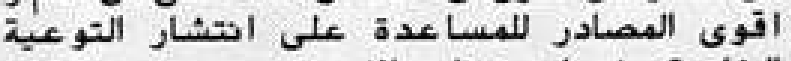

لم تذكر غالبية المترددات ارتفاع تكلفة خدمات تنظيم الاسرة او اى خدمة اخرى تقدم عبر تلك المنافذ كاحد الاسباب لترك الخدمة الا ان الاج فتط هن اللاتى اكدن على استعد اد هن لد في المزيد للحصول على مستوى اعلى للجحودة بالنسبة لخدمات تنظيم الاسرة. من هئا تتضح اهمية تطوير الخدمة للوصول الى اهم اهداف استرداد النفقات المتعلقة بها. اكدت 4^٪ من المتزددات اللاتى تمت مقابلتهن على عزمهن على ان يظلوا يترددن على ثفس مركز تقديم الخذمة الذى تمت به مقابلتهن بدون اى اختلاف يذكر بين مركز و 


\section{التوصيات}

يوجد تد اخلات في وصف خصانص المترددات على مختلف منا فذ تقد يم خدمات تنظيم الاسرة بدرجة معقولة و لكن مع وجود درجة من الاختلاف لكل منفذ خدمة فيما يتعلق بطبيعة المترددات اللاتى يخدمهن. لذلك يجبب على المديرين و مخططى البرامج الاستعانة بالاسباب التى تذكر ها المترددات لاختيار هن لوحدة تنظيم الاسرة و ذلك لوضع الاستراتيجيات الاعلامية و التنفيذية و التى تضمن تحقيق هذة الغايات و كذلك رفع مستوى الخدمة . كما يجب وضع اسباب عدم رضا المترددات عن الخدمة محل الدراسـة.

$$
\begin{aligned}
& \text { اسباب انتقال المترددات } \\
& \text { من مركز الى اخر المترد }
\end{aligned}
$$

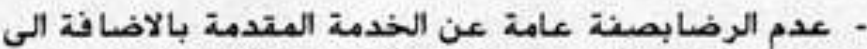

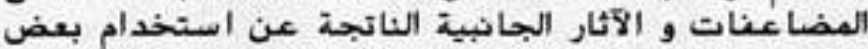

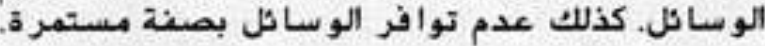

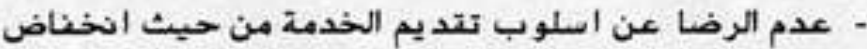

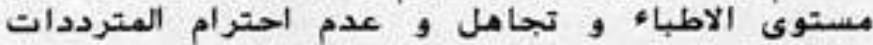
بالاضافة الى عدم معاملتهن المعاملة اللائقة مع ارتشاع المداع تكاليف تقد يم الخدمة
قلة معرفة المترددات باماكن اخرى لتقديم خدمات تنظيم الاسرة و من هـا تظهر الحاجة الى مزيد من الجهد لتو عية التية

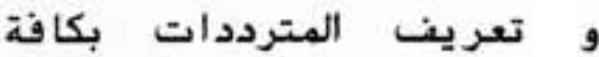
الجهات المتاحة . ليس هناك ثمط ثابت للانتقال بين منفذ لتقد يم الخدمة و آخر فجميع تلك المنافذ تكسب

و تخسر مترددات من بعضهم البعض. الا ان اكثر من يخسرون المترددات هم الاطباء الخصوصيون حيث تنتقل المترددات عليه الى اطباء خصوصين آخرون ثم الى العيادات التابعة لمشروع CSI ثم الى المستشفيات. فقد وجد ان اعلى نسبة مترددات على العياد ات التابعة لمشرو ع CSI هن في حقيقتهن منتقلات من عيادات الاطباء الخاصة . كما و انه غالبا ما تنتقل المترددات من العيادات التابعة لهذا المشروع الى عيادات الاطباء الخاصة ثم الى الوحدات الريفية ثم الى المستشفيات ـ و من هنا يتضح اهمية در اسة اسباب تلك الانتقالات عند اعادة تقييم و تحديد المجموعات المستهدفة من مراكز تقديم الخدمة.

لم يحظ رفع تكاليف تقد يم خدمات تنظيم الاسرة بقبول اغلبية المترددات. الا اته اذا كان هناك ارتفاع طفيف في اسعار تقد يم الخدمة بالمر اكز او الوحدات الر يفية و مر اكز الامومة و الطفولة و كان مصحوبا بتقدم و ارتفاع فى مستوى تلك الخدمات، عند ثذ سيحظى بقبولهن، حيث لا زالت نسبة كبيرة من المترددات تعتبرن تكاليف تقد يم الخدمة معقولة. لذا يجب ان يشتمل تطوير الخدمة المقدمة على تطور فى الخدمات الخاصة بامر اض النساء و التوليد بجانب خدمات تنظيم الاسرة خاصة للسيدات ذات الدخل الضنيل بين الريفيات اللاتى يتحتم عليهن الانتقال لمسافات طويلة للوصول الى العيادات الحضرية للحصول على تلك الخدمات. 


\section{الاستفادة من نتائج البحث}

افادت نتانج هذا البحث المسنولين بمركزالاعلام و التعليم و الاتصال بشكل كبير

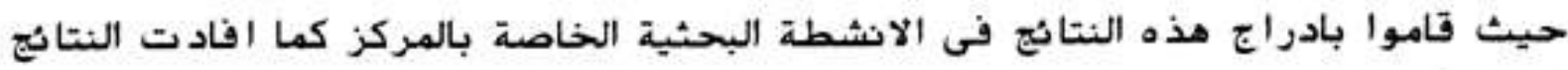

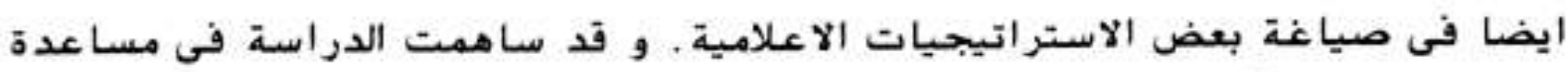

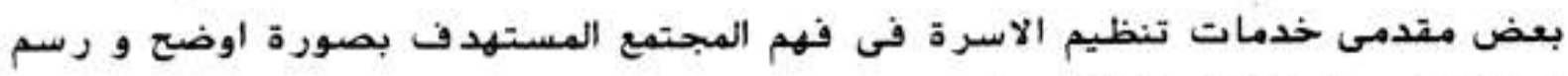
خطط تسويقية لتنشيط الخدمة. 